\title{
Feasibility and Acceptability of an mHealth-Based Approach as an HIV Prevention Strategy Among People Who Use Drugs on Pre-Exposure Prophylaxis
}

This article was published in the following Dove Press journal: Patient Preference and Adherence

\author{
Roman Shrestha' \\ Frederick L Altice (D) ${ }^{2}$ \\ Elizabeth DiDomizio² \\ Brian Sibilio ${ }^{3}$ \\ Yerina S Ranjit ${ }^{2}$ \\ Michael M Copenhaver ${ }^{3}$ \\ 'Aasaman Nepal, HIV Prevention Group, \\ Lalitpur, Nepal; ${ }^{2}$ Section of Infectious \\ Diseases, Department of Internal \\ Medicine, Yale School of Medicine, New \\ Haven, CT, USA; ${ }^{3}$ Department of Allied \\ Health Sciences, University of \\ Connecticut, Storrs, CT, USA
}

\begin{abstract}
Introduction: There has been increasing interest in the use of mHealth technology in health care. To our knowledge, however, there is a lack of empirical evidence on the utilization of text messaging services (short message service; SMS) for HIV prevention among opioiddependent people who use drugs (PWUD). As part of our formative work, we conducted an in-depth feasibility and acceptability study on the use of SMS reminders for HIV prevention in this risk group.
\end{abstract}

Methods: Forty HIV-negative, opioid-dependent PWUD who are currently taking preexposure prophylaxis (PrEP) were enrolled in the study. Participants received daily PrEP text reminders and weekly HIV risk reduction-related messages, which were developed using a user-centered approach. Participants were assessed at baseline and immediately postintervention. Following the post-intervention assessment, participants completed an indepth qualitative interview.

Results: Feasibility of text messaging service was high, as assessed by participants' willingness to receive text messages $(100 \%)$, retention $(95 \%)$, and successful delivery of text messages $(97 \%)$. Results further showed that participants were satisfied and perceived the use of daily PrEP reminder text messages as valuable and acceptable [mean: 75.0 (range 0-100)]. Whereas, acceptability for the weekly text messages on HIV risk reduction was $60.3( \pm 15.6)$, with $58.3 \%$ recommending them for future use. Thematic data exploration revealed important information for understanding and refining SMS content as well as logistical preferences.

Conclusion: Our findings provide preliminary evidence of the feasibility and acceptability of a text messaging-based approach as a potential tool for primary HIV prevention to improve PrEP adherence and HIV risk reduction among this underserved population. HIV risk reduction text messages need further modifications to become more appealing, with participant feedback taken into consideration.

Keywords: opioid use disorder, pre-exposure prophylaxis, text messaging, mobile technology, HIV risk behaviors

\section{Introduction}

The volatile opioid epidemic ushering in rising drug injection have threatened to trigger a resurgence of HIV in the United States. ${ }^{1,2}$ Recent estimates show that 2.4 million people aged 12 years and older have an opioid-use disorder (OUD), with 948,000 using heroin in the past year. ${ }^{3}$ Evidence further suggests that a high proportion of individuals who misuse prescription opioids (10-20\%) transition to injection, ${ }^{4,5}$ which contribute to considerable risk for HIV transmission from both drug- (eg, sharing of needles and
Correspondence: Roman Shrestha Asaman Nepal, HIV Prevention Group, Ring Road, Lalitpur 44700, Nepal Tel +977-9849783। 32

Email romanshre@gmail.com 
syringes for injection drug use) and sexual-related risk behaviors (eg, condomless sex). ${ }^{6}$ With increasing OUD and drug injection, opioid-dependent people who use drugs (PWUD) continue to remain a population at high-risk for HIV infection and transmission.

Pre-exposure prophylaxis (PrEP) has emerged as an effective tool for reducing the HIV epidemic and is recommended for high-risk populations, which includes PWUD. $^{7}$ Recent PrEP studies on a large scale have shown PrEP to be highly efficacious $(>90 \%)$ in reducing HIV transmission to individuals who are at increased risk for infection, as well as safe and well-tolerated..$^{8-12}$ Importantly, the Achilles Heel to PrEP efficacy is adherence to medication-taking (at least four doses per week for men and daily use in women). ${ }^{13,14}$ Therefore, as PrEP use expands, novel, less intensive, and cost-effective approaches are needed that are aimed at improving PrEP adherence among opioid-dependent PWUD given multifaceted determinants of non-adherence in this risk group. ${ }^{15-19}$

Mobile technologies for health (mHealth) are effective and cost-effective strategies as ways to improve individual and public health. ${ }^{20-23}$ Text messaging, or short message service (SMS), particularly represent a convenient and low-cost way to enhance health behaviors, such as treatment adherence, due to the universal nature of this technology on mobile devices. ${ }^{24,25}$ This technology also has the potential to circumvent barriers to standard-of-care adherence interventions, especially in groups that are difficult to track. Although still in the early stages, text messaging-based interventions have started to show efficacy in supporting adherence to PrEP for MSM and transgender women in randomized controlled trials (RCT). ${ }^{26}$ Taken together, high-risk opioid-dependent PWUD represent feasible and crucial target for such innovative mHealth approaches, as it has yet to be assessed among this population.

To our knowledge, there is a lack of evidence-based research regarding the utilization of text messaging-based approaches for HIV prevention among high-risk opioiddependent PWUD and, thus, formative work is needed to guide the integration and implementation of mHealth strategies in HIV prevention efforts in this risk group. In response, we conducted an in-depth feasibility and acceptability study on the use of text messaging service to promote adherence to PrEP and HIV risk reduction among this sample in the context of a methadone maintenance program (MMP). Such information is crucial to optimize PrEP programs in addiction treatment settings, where high-risk opioid-dependent individuals are concentrated and are ideal settings to implement primary HIV prevention interventions among this risk group. The aim of this study was largely exploratory and meant to assess the initial feasibility and acceptability of the use of SMS and text messages in preparation for a larger randomized controlled trial $(\mathrm{RCT})$.

\section{Materials and Methods Focus Groups and Text Messages Development}

Text messages were developed with a user-centered approach. ${ }^{27}$ Using two focus groups, we assessed the feasibility of using text messages to improve medication adherence among this population and to obtain feedback on the thematic content of the text messages. Each focus group consisted of five participants who reported HIV risk behaviors and were HIV-negative, methadone maintained (these participants were not enrolled in the current study). Participants were given from a list of predetermined text message stems and then went on to select, modify, and create twenty-six text message reminder stem tailored to this study. We covered the five core components of PrEP adherence including: i) making the most of PrEP as an active health manager; ii) reducing drug risk and taking PrEP; iii) PrEP adherence and sex risk reduction strategies; iv) negotiating partner support for HIV prevention (Table 1). ${ }^{29}$ HIV risk reduction behavioral intervention sessions were also included in the focus group content. ${ }^{28,29}$ The focus groups were effective in generating broad barriers and facilitators for adherence, along with preferences for reminder text messages in order to promote adherence through use of an mHealth intervention. Based on the focus groups results, ten daily PrEP reminder messages and sixteen weekly text messages were identified that fell into four distinct HIV risk reduction-related themes (Table 1).

\section{SMS Text Messaging Platform}

The automated SMS text messaging system was developed in the Telerivet mobile messaging platform. At the time of enrollment, participants provided their mobile phone numbers and asked their preferred time to receive text messages, and this information was then programmed through Telerivet's platform to be delivered at the participant specified times. All messages were stored on the Telerivet 
Table I Example of SMS Text Messages

\begin{tabular}{|c|c|c|c|}
\hline Topic & Frequency & Time & Messages \\
\hline \multirow[t]{2}{*}{ PrEP reminder } & \multirow[t]{2}{*}{ Daily } & Morning & $\begin{array}{l}\text { - Good morning! This is your PrEP reminder. } \\
\text { - This is your morning PrEP reminder. Have a great day! } \\
\text { - Start your day off right. Remember to take your PrEP. } \\
\text { - It is going to be a great day. Remember to take your PrEP. } \\
\text { - Hope you have a great day. This is your PrEP reminder. }\end{array}$ \\
\hline & & PM & $\begin{array}{l}\text { - "Hint, hint" Time for your PrEP. } \\
\text { - This is your PrEP reminder. } \\
\text { - Before you call it a day, remember your PrEP. } \\
\text { - Reminder - take your PrEP (if you have not already). } \\
\text { - Do not forget to take your PrEP. }\end{array}$ \\
\hline \multicolumn{4}{|l|}{ Week I } \\
\hline $\begin{array}{l}\text { Making the most of prep as an } \\
\text { active health manager }\end{array}$ & \multicolumn{2}{|l|}{ Weekly } & $\begin{array}{l}\text { - You and your health-care provider are a team. Work together to get the best } \\
\text { care. } \\
\text { - PrEP works if you take one pill on a daily basis. } \\
\text { - Remember - continue to use condom and clean needle while on PrEP. } \\
\text { - Think before you use illicit drugs or have unsafe sex. Both of them negatively } \\
\text { affect your health and treatment option. }\end{array}$ \\
\hline \multicolumn{4}{|l|}{ Week 2} \\
\hline Reducing drug risk and taking PrEP & \multicolumn{2}{|l|}{ Weekly } & $\begin{array}{l}\text { - Drug use can compromise your health: Stay away from it. } \\
\text { - The only way to prevent harm of drug use is to abstain from using drugs: Stay } \\
\text { away. } \\
\text { - Always CARE about yourself and others, NOT share. } \\
\text { - If you inject drugs \& do not have new needle, clean needle with bleach. }\end{array}$ \\
\hline \multicolumn{4}{|l|}{ Week 3} \\
\hline $\begin{array}{l}\text { PrEP Adherence and sex risk } \\
\text { reduction strategies }\end{array}$ & \multicolumn{2}{|l|}{ Weekly } & $\begin{array}{l}\text { - Condoms = peace of mind. Wear one and make sure your partner does too. } \\
\text { - Great lovers use condom, always have it handy. } \\
\text { - Play it safe: The first step to having safer sex is being sober. } \\
\text { - It is your life, CARE about safer sex. }\end{array}$ \\
\hline \multicolumn{4}{|l|}{ Week 4} \\
\hline $\begin{array}{l}\text { Negotiating partner support for } \\
\text { HIV prevention }\end{array}$ & \multicolumn{2}{|l|}{ Weekly } & $\begin{array}{l}\text { - Condoms are sexy. STIs and reinfection are not. Talk to your partner about } \\
\text { using condoms today. } \\
\text { - Be respectful and responsible. Talk with your partner about condoms. } \\
\text { - Talk with your partners about STIs. Hearing it from your partner beats hearing } \\
\text { it from your provider. } \\
\text { - Do the right thing. Talk to your partner about safer sex. }\end{array}$ \\
\hline
\end{tabular}

website. No identifiers, however, other than mobile phone numbers were stored on the website to minimize privacy concerns.

Before pilot testing the text messages with participants, it was tested by members of the research team to address any technological difficulties. Four research team members agreed to receive the text messages and supplied feedback regarding the content and the delivery of the text messages. We then tested the messages with five participants (data not included in the current analysis) and made modifications based on feedback received from all parties.

\section{Piloting the Text Messages Study Setting and Participants}

This convenience sample was recruited from an inner-city MMP located in New Haven, Connecticut. Inclusion criteria were: age 18 years or older, confirmed HIV-negative, newly prescribed PrEP (within the past 30 days), self-reported drug- (eg, sharing of needles and syringes/other injection 
equipment) or sex-related (eg, multiple sex partners, condomless sex) HIV risk behaviors, ownership of working mobile phone, enrolled in MMP, and the capacity to provide informed consent. Participants were recruited and enrolled between September 2016 and July 2017 who agreed to receive text messages over a 4 -week intervention period.

\section{Procedures}

Recruitment strategies included use of flyers, word-ofmouth, peers, and direct referral from MMP counselors. Interested individuals who met the eligibility criteria were enrolled in the study and provided written consent prior to completing the assessments. During their initial visit, participants were informed about the use of text messaging throughout duration of the program (4 weeks).

Participants received two types of text messages: 1) a daily text message with reminders to take their daily dose of PrEP timed to match with individually stated dosing preferences, and 2) four weekly text messages related to HIV risk reduction (Table 1). Each week we would collect, double check, and update participant mobile phone numbers, as it was imperative to have the correct information for this study.

No control condition was included given the lack of pilot data to support this mHealth approach. Participants were paid only for their time to complete structured interviews and not for their performance in using SMS. The study was approved by the Institutional Review Board at the [BLINDED FOR REVIEW] and by the board from the MMP clinic.

\section{Assessments Quantitative Assessment}

An audio computer-assisted self-interview (ACASI) was used to assess all quantitative measures. These assessments were self-administered by respondents in a private room using a laptop computer equipped with audio headphones. Themes that were assessed included: demographic and social characteristics, homeless status, current methadone dose, and perceived HIV risk. Additional measures are described in detail below:

\section{HIV Risk Behaviors}

The HIV risk assessment used in this study was adapted from National Institute on Drug Abuse (NIDA)'s Risk Behavior Assessment. It was used to measure several aspects of HIV risk behaviors, such as a measurement of "any" high-risk behavior (sexual or drug-related) and measurements of event-level (ie, partner-by-partner) behaviors. ${ }^{30}$ Examples of HIV risk behaviors included injection of illicit drugs, number of sexual partners, and frequency of condom use, all within the last 30 days.

PrEP adherence was assessed within the last 30 days using a self-reported, 3-item scale validated by Wilson et al (2016). The mean of the three different items was calculated to produce the summary scale, with higher score indicating better adherence $(0-100) .{ }^{31}$

Feasibility of text messaging approach was assessed throughout the study via process indicators including number of individuals screened, enrolled, and retained throughout the study period. Furthermore, we assessed performance of the Telerivet system to deliver text messages (eg, successful delivery of messages), was obtained from Telerivet's website.

Acceptability of text messages was assessed using an adapted version of a series of 10-item acceptability rating profile. $^{32}$ Acceptability assessments were done separately for both weekly text messages and daily PrEP reminders related to HIV risk reduction. During the post-intervention assessment, participants rated the extent to which they agree with each acceptability statement using a 5-point Likert scale $(0=$ strongly disagree to $4=$ strongly agree). Examples of the assessment for the daily PrEP reminders included "I liked the number of daily PrEP reminder text messages received from the program", and "I liked the timing of the daily PrEP reminder text messages sent to me." Examples of the weekly text messages assessment included "I feel like the weekly content text messages were a good source of information", and "I feel like the weekly content text messages were often annoying." 26 Acceptability scores were calculated by adding the scores and converting them into a score on the $0-100$ scale with higher values indicating greater acceptability.

\section{Qualitative Assessment}

All qualitative interviews were semi-structured around a set of carefully predetermined interview guides (Table 2). These guides were brief and semi-structured to encourage free-flowing discussion between interviewer and participant. The qualitative interviews were conducted following the intervention (at $\mathrm{T}_{4}$ ) to elicit additional feedback about the text messages and the overall approach. Specifically, interviews explored ease of understandings and problems with text messages, overall experience and satisfaction with text messages, likelihood of using the system to improve health outcomes in the future, and feedback on the reminder 
Table 2 Interview Guide for Focus Group Sessions

- Describe how relevant were the text messages you received from
our program?
- Describe how successful was the text messaging approach we used
to encourage you to change your behaviors? What behaviors do
you think were most likely to change and why?
- How satisfied are you with the text messaging approach we used
in our program? Give some examples.
- How did you feel about the content, frequency, and delivery time
of the text messages received? Give some examples of ones you
liked or did not like.
- Did you have any problems with receiving/accessing the text
messages on your phone?
- Describe some of the issues or barriers (if any) you came across
while receiving text messages?
- How would you feel about the text messages being delivered in
a different way? Please explain.
- Would you recommend us to incorporate text messaging services
in our future studies and why?
- What do you think would be helpful for us to consider in terms of
better designing the text messages?

text messages. All qualitative interviews were audiotaped and transcribed.

\section{Data Analyses}

SPSS software program was used for quantitative data analyses. Descriptive statistics were performed for demographic, sexual and substance use profile characteristics of the study population. The means and standard deviations of continuous variables and frequencies and percentages of categorical variables were derived to assess participants' characteristics, adherence to PrEP, and acceptability of SMS text messaging.

Qualitative data were analyzed following a thematic analysis approach, which applies several qualitative data analysis procedures such as inductive analysis and crosscase analysis. Emergent themes and patterns were identified directly in the transcripts during the first inductive analysis. Two research team members completed the coding process for each transcript. A master list of themes was then compiled to reflect overarching themes. The research team members scheduled regular meetings to discuss participant narratives, to contextualize differences, to build consensus, and to cross-case analyze decisions of emerging themes.

\section{Results}

\section{Participant Characteristics}

Participants in the study were predominantly in their mid40 s (mean $=44.8$ years, $\mathrm{SD}=11.8$ ), heterosexual $(77.5 \%)$, high school graduates $(75.0 \%)$, unemployed $(92.5 \%)$, and earned less than $\$ 10,000 /$ year $(77.5 \%)$. Over one-quarter of study participants $(27.5 \%)$ reported homelessness in the past month (30 days). All participants had been enrolled in an inner-city MMP before entering this study and were maintained on a stable dose of methadone (mean=78.5 mg, $\mathrm{SD}=25.8)$.

HIV risk behaviors (self-reported) showed to be highly prevalent in this sample. Self-perceived risk of contracting HIV ranged from medium to high in most participants $(80.0 \%)$ based on their own behavior. There was a mean adherence score of $87.6( \pm 18.6)$ for having taken PrEP in the past 30 days. Details of participant characteristics are provided in Table 3.

\section{Feasibility of SMS Text Messaging}

Of the 173 individuals who underwent screening, 40 were eligible and enrolled in the study. All participants (100\%) agreed at baseline to receive text messages as part of the intervention. Of the total text messages sent $(2,635)$ during the intervention period, almost all (97\%) were successfully delivered as scheduled. Although participants were made aware that the text messaging feature was a one-way messaging system, $29.4 \%$ attempted to reply to the text message that was sent. Follow-up assessments completion was high, with $95 \%$ retention at post-intervention. None of the participants reported any technical difficulties in receiving or understanding text messages. Similarly, there were no technical issues reported by the research staff while setting up the text messaging platform in Telerivet.

\section{Acceptability of SMS Text Messages Prep Text Reminders}

Our results showed that the participants perceived the use of daily PrEP dose reminder text messages as valuable and acceptable and were satisfied with the experience. As shown in Figure 1, the mean acceptability (range: 0-100) for the daily PrEP reminder was $75.0( \pm 11.7)$. This indicates that participants had strong agreement about the acceptability of the daily PrEP reminder text messages. The vast majority of participants liked the daily PrEP reminder text messages $(81.0 \%)$ and reported that the text messages assisted them in remembering to take PrEP 
Table 3 Baseline Characteristics of the Participants

\begin{tabular}{|c|c|c|}
\hline Variable & Frequency & $\%$ \\
\hline Age: Mean, years $( \pm S D)$ & $44.8( \pm 11.8)$ & \\
\hline \multicolumn{3}{|l|}{ Sex } \\
\hline Male & 22 & 55.0 \\
\hline Female & 18 & 45.0 \\
\hline \multicolumn{3}{|l|}{ Sexual orientation } \\
\hline Heterosexual & 31 & 77.5 \\
\hline Homosexual, gay, or lesbian & 3 & 7.5 \\
\hline Bisexual & 6 & 15.0 \\
\hline \multicolumn{3}{|l|}{ Ethnicity } \\
\hline White & 23 & 57.5 \\
\hline African American & 13 & 32.5 \\
\hline Hispanic or Latino & 3 & 7.5 \\
\hline Other & I & 2.5 \\
\hline \multicolumn{3}{|l|}{ Marital status } \\
\hline Married & 12 & 30.0 \\
\hline High school graduate & 30 & 75.0 \\
\hline Employed & 3 & 7.5 \\
\hline \multicolumn{3}{|l|}{ Income } \\
\hline$<\$ 10,000$ USD & 31 & 77.5 \\
\hline$\$ 10,000-\$ 19,999$ USD & 7 & 17.5 \\
\hline$\geq \$ 20,000$ USD & 2 & 5.0 \\
\hline Homeless (past 30 days) & II & 27.5 \\
\hline Methadone dose, mean (mg) & $78.5( \pm 25.8)$ & \\
\hline Injected illicit drugs (past 30 days) & 29 & 72.5 \\
\hline Shared injection equipment (past 30 days) & 25 & 62.5 \\
\hline Been sexually active (past 30 days) & 32 & 80.0 \\
\hline Number of sexual partners (past 30 days) & $\mathrm{n}=32$ & \\
\hline 1 & 13 & 40.6 \\
\hline $2-5$ & 15 & 46.9 \\
\hline$\geq 6$ & 4 & 12.6 \\
\hline Always used condom with casual partner & $\mathrm{n}=32$ & \\
\hline No casual partner & 5 & 15.6 \\
\hline No & 13 & 40.6 \\
\hline Yes & 14 & 43.8 \\
\hline \multicolumn{3}{|l|}{ Current risk of getting HIV } \\
\hline Low & 8 & 20.0 \\
\hline Medium & 19 & 47.5 \\
\hline High & 13 & 32.5 \\
\hline PrEP adherence & $87.6( \pm 18.6)$ & \\
\hline
\end{tabular}

Abbreviations: SD, standard deviation; HRBS, HIV risk-taking behavior scale; PrEP, pre-exposure prophylaxis.

(78.3\%). Similarly, most participants expressed that they liked both the timing $(81.1 \%)$ and the content $(70.5 \%)$ of the daily PrEP reminders, and that they would recommend it for future programs $(83.8 \%)$. Furthermore, the majority of the participants $(73.0 \%)$ reported that they would prefer two-way text messaging (eg, be able to reply and get response) as opposed to our one-way messaging.

\section{HIV Risk Reduction Texts}

Acceptability of the weekly text messages for targeting HIV prevention and risk reduction was $60.3( \pm 15.6)$. Over half of the participants liked the weekly text messages $(62.1 \%)$ and $71.7 \%$ reported that the messages encouraged them to reduce their engagement in risk behaviors. Approximately two-thirds of the participants liked the timing of the messages $(65.8 \%)$; however, only $53.9 \%$ of the participants liked the actual content of weekly text messages and $58.3 \%$ would recommend them for future programs (Figure 1).

\section{Qualitative Results}

Data analysis from the semi-structured interviews revealed the following primary themes regarding participants' attitudes and experiences surrounding the text messages: i) usefulness of the service; ii) general experience and convenience of use; iii) barriers to use; and iv) recommendations for future programs. The themes and subthemes identified from the qualitative data are described in detail in Table 4.

\section{Usefulness of the Service}

Participants valued the text messages and perceived that the reminders encouraged them to change their behaviors, particularly their adherence to PrEP. Some of the participants reported that because they considered themselves to be adherent, there was not a strong need for them to receive additional reminders. Still, they acknowledged having the occasional lapses in adherence and appreciated the extra support that the reminder text messages provided:

Text messages were very helpful as far as reminding me to take my meds [PrEP] .... To be honest, I sometimes forget to take that pill, then I get your message 'Hint, hint, take your PrEP' ... I like these messages because they tell us to take care of our health.

\section{General Experience and Convenience of Use}

Most participants indicated positive experiences with the use of text messages when asked about it. They were comfortable with the technology and were easily able to access and read their text messages, with no reports of technical difficulties in receiving the messages. Overall, 


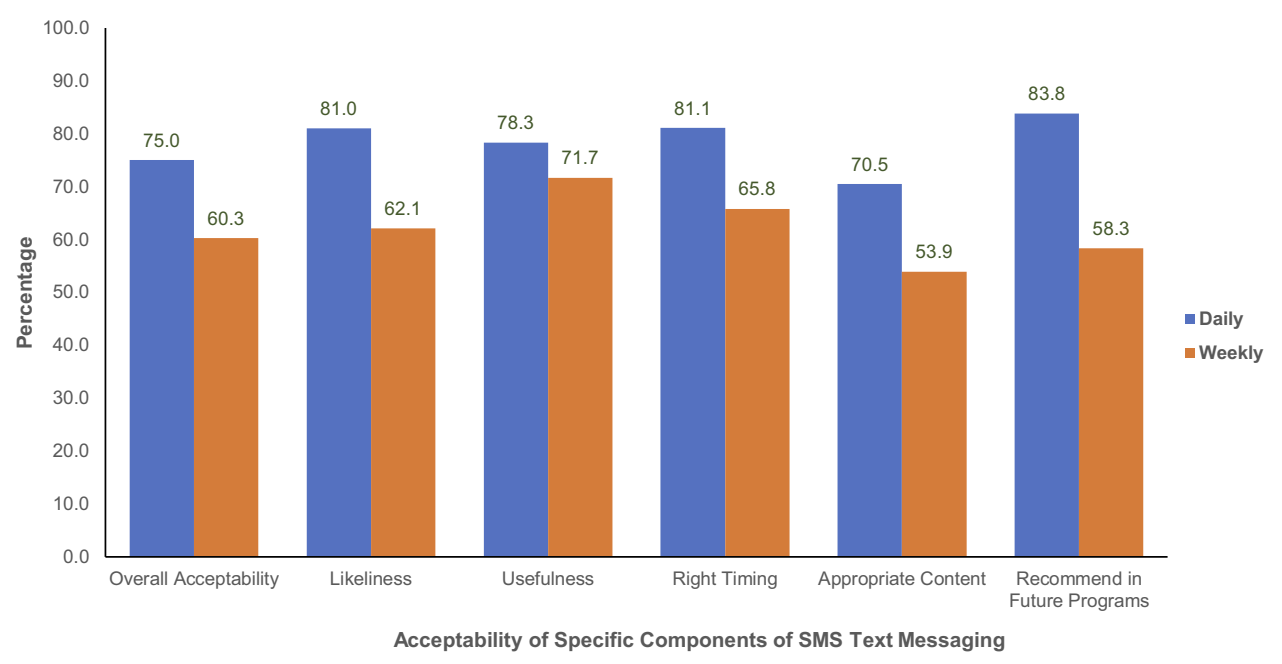

Figure I Acceptability of Specific Components of SMS Text Messaging.

participants communicated favorable attitudes about the use of text messaging for HIV prevention:

I like how you had different text messages for different days ... They [text messages] were always right on time. Every morning at 8:00 am I get these [text messages] and I take the pill $[\mathrm{PrEP}]$ right after ...

While most patients reported positive experiences with the text messages, a few participants described feeling bothered sometimes at the text messages they were receiving:

Sometimes they were a little annoying. My phone kept buzzing because of all the texts I was receiving from you. [program].

\section{Barriers to Use}

Although most participants indicated positive attitudes about the use of text messaging, a few expressed helpful concerns related to this method of communication. Privacy: Some participants brought up issues related to the need for privacy when asked about the challenges or concerns of text messaging. Some were concerned that other people could read messages containing sensitive information on their phone if they did not delete the messages immediately and this could be embarrassing or stigmatizing:

One day, my daughter was playing a game on my phone, and all of sudden, all these messages about condom use and sex started to come through ... I worry about other people seeing my texts. Many people out there have no idea what it [PrEP] is for, and they would not understand they will probably think I am infected and tell others.
Issues with mobile phone: The challenge commonly reported by the participants that affected their ability to receive text messages was running out of minutes, and frequently changing phone numbers without advising the research staff:

Last month, I ran out of minutes and didn't get any texts from you guys [program] ... I think I didn't give you [research staff] my new number. I didn't get your messages for about a week.

Frequency of text messages: Almost all participants liked the frequency of daily PrEP reminders. Some participants, however, pointed out concerns about the number of weekly text messages that they received from the program related to HIV risk reduction:

It was annoying to receive four messages all at the same time. I'd suggest you guys [research staff] have a few hours gap in between messages ... Maybe there should be like an opt out option, so if someone didn't have the problem, they don't have to receive certain messages.

\section{Recommendations for Future Programs}

Tailored content: A few participants noted that personalizing the messages and varying the content could improve the text messaging experience. Participants suggested that the research staff should first meet with the participants to discuss their specific needs, and then tailor messages accordingly:

I'm inclined to read it [text message] if it said, 'Hi $\mathrm{X}$ [recipient's name]'. I think it has more personal flavor to the message ... The messages would be better if you 
Table 4 Themes and Subthemes Identified from Qualitative Data

\begin{tabular}{|c|c|c|}
\hline \multicolumn{2}{|l|}{ Themes } & Participant Quotes \\
\hline \multicolumn{2}{|c|}{ Usefulness of the service } & $\begin{array}{l}\text { "Text messages were very } \\
\text { helpful as far as reminding me } \\
\text { to take my meds [PrEP]." } \\
\text { "To be honest, I sometimes } \\
\text { forget to take the pill, then } \\
\text { I get your message 'Hint, hint, } \\
\text { take your PrEP'." }\end{array}$ \\
\hline \multicolumn{2}{|c|}{$\begin{array}{l}\text { General experience and } \\
\text { convenience of use }\end{array}$} & $\begin{array}{l}\text { "They [text messages] were } \\
\text { always right on time. Every } \\
\text { morning at 8:00 am I get these } \\
\text { [text messages] and I take the } \\
\text { pill [PrEP] right after." } \\
\text { "Sometimes they were a little } \\
\text { annoying. My phone kept } \\
\text { buzzing because of all the } \\
\text { texts I was receiving from you } \\
\text { [program]." }\end{array}$ \\
\hline \multirow[t]{3}{*}{ Barriers to use } & Privacy & $\begin{array}{l}\text { "One day, my daughter was } \\
\text { playing a game on my phone, } \\
\text { and all of sudden, all these } \\
\text { messages about condom use } \\
\text { and sex started to come } \\
\text { through." } \\
\text { "I worry about other people } \\
\text { seeing my texts. Many people } \\
\text { out there have no idea what it } \\
\text { [PrEP] is for, they would not } \\
\text { understand - they will } \\
\text { probably think I am infected } \\
\text { and tell others." }\end{array}$ \\
\hline & $\begin{array}{l}\text { Issues with } \\
\text { mobile } \\
\text { phone }\end{array}$ & $\begin{array}{l}\text { "Last month, I ran out of } \\
\text { minutes and didn't get any } \\
\text { texts from you guys } \\
\text { [program]." } \\
\text { "I think I didn't give you } \\
\text { [research staff] my new } \\
\text { number. I didn't get your } \\
\text { messages for about a week." }\end{array}$ \\
\hline & $\begin{array}{l}\text { Frequency of } \\
\text { text } \\
\text { messages }\end{array}$ & $\begin{array}{l}\text { "It was annoying to receive } \\
\text { four messages all at the same } \\
\text { time. l'd suggest you guys } \\
\text { [research staff] to have a few } \\
\text { hours gap in between } \\
\text { messages." } \\
\text { "Maybe there should be like } \\
\text { an opt out option, so if } \\
\text { someone didn't have the } \\
\text { problem, they don't have to } \\
\text { receive those messages" }\end{array}$ \\
\hline
\end{tabular}

(Continued)
Table 4 (Continued).

\begin{tabular}{|c|c|c|}
\hline \multicolumn{2}{|l|}{ Themes } & \multirow[b]{2}{*}{$\begin{array}{l}\text { Participant Quotes } \\
\text { “'m inclined to read it [text } \\
\text { message] if it said, 'Hi } \\
\text { X [recipient's name]'. I think it } \\
\text { has more personal flavor to } \\
\text { the message." } \\
\text { "The messages would be } \\
\text { better if you could relate } \\
\text { them to our [participants'] } \\
\text { personal needs. I mean if I do } \\
\text { not inject, why should } \\
\text { I receive texts about do not } \\
\text { share. That makes no sense." }\end{array}$} \\
\hline $\begin{array}{l}\text { Recommendations } \\
\text { for future } \\
\text { programs }\end{array}$ & $\begin{array}{l}\text { Tailored } \\
\text { content }\end{array}$ & \\
\hline & $\begin{array}{l}\text { Bi-directional } \\
\text { and } \\
\text { reinforcing } \\
\text { messages }\end{array}$ & $\begin{array}{l}\text { "Why can't we just reply to } \\
\text { your messages and get hold of } \\
\text { one of you [research staff]." } \\
\text { "Something like, 'Great job', } \\
\text { after taking meds [PrEP] } \\
\text { would be very encouraging." }\end{array}$ \\
\hline & $\begin{array}{l}\text { Multimedia } \\
\text { content }\end{array}$ & $\begin{array}{l}\text { "Umm, having emojis, like } \\
\text { smiley faces, or funny } \\
\text { pictures, that go along with } \\
\text { the text messages." }\end{array}$ \\
\hline
\end{tabular}

could relate them to our [participants'] personal needs. I mean if I don't inject, why should I receive texts about don't share. That makes no sense.

Bi-directional: The majority of participants expressed a strong preference for the two-way SMS text messaging feature. Participants reported that the ability to reply to messages and receive further information may help to increase motivation to engage with the program and improve health outcomes. Other text-related logistical suggestions included the ability to have a "snooze" option and reinforcement messages to motivate participants to change their risk behaviors:

Why can't we just reply to your messages and get hold of one of you [research staff]. Sometimes I'm not home where my pills are. I want it to be able to snooze the text messages, just like my alarm you know, so that I don't forget my meds [PrEP] when I get home ... Something like, 'Great job', after taking meds [PrEP] would be very encouraging.

Multimedia Content: A few participants recommended adding multimedia components in the text messages (eg, emojis, pictures) to enhance interaction and engagement: 
Umm, having emojis, like smiley faces, or funny pictures, that go along with the text messages.

\section{Discussion}

As emerging mobile technologies increase, access to and utilization of these mHealth services become increasingly crucial as mHealth-based approaches are ideally positioned as platforms for delivering evidence-based HIV prevention efforts, particularly within resource-limited settings. [33] As such, the findings from this study provide exploratory evidence of feasibility and acceptability of the text messaging-based approach as an additional HIV risk reduction strategy to enhance adherence to and to support HIV prevention among this underserved population. As part of the formative process, it was imperative to integrate input from the target population in order to successfully develop a culturally appropriate text messaging approach. ${ }^{34}$ Feedback from participants provided important information for understanding messaging preferences and operational procedures to inform further refinement of the text messages and overall approach.

Significant findings from this pilot study show us that access to mobile phones among our sample was quite high (97.6\% of total screened individuals) and that all participants were interested in receiving SMS support text messages. Additionally, neither participants nor research staff reported any technological complications that negatively impacted the implementation of our text messaging approach, aside from running out of minutes and occasionally changing cell phone numbers. The high retention rate $(>95 \%)$, paired with that fact that almost all messages were delivered as intended, suggests that a text messaging approach is highly feasible and has the potential to be easily integrated within existing HIV prevention interventions in common drug treatment settings (eg, MMP). This reflects the generally positive outcomes of studies that have evaluated the feasibility of text messaging and mHealth interventions for HIV prevention and care in other settings. ${ }^{26,35-39}$ Furthermore, initial experience in text message content and platform development, and overall implementation suggests that this method may be a relatively cost-effective tool to support HIV prevention efforts among this risk population, given their widespread use of mobile phones, in contrast to their use of smartphones and internet resources. ${ }^{23,33,40}$

Moreover, findings from both quantitative and qualitative responses revealed that participants were generally positive toward text messages, particularly daily PrEP reminders. Overall, these results strengthen the evidence base that a text messaging approach is acceptable among this risk group. ${ }^{33}$ Findings from this study are promising as it targets a high-risk population who will potentially benefit from such an innovative approach.

Several important lessons were learned about how to improve this strategy. First, approximately $40 \%$ of participants did not respond positively about the weekly text messages regarding HIV risk reduction. Many participants did not like the content of the messages they received, even though they generally liked the idea of weekly timed messages. Certain explanations for this include perceived breach of confidentiality/privacy, preference for messages that are encoded, and lack of two-way text messages that allow them to interact with the staff. ${ }^{41}$ As such, findings from qualitative interviews provided important insights into how text messages - primarily the weekly messages may be further refined for optimal use in the future studies, including tailoring specific messages to individuals who may benefit from them (rather than delivering one-size-fits -all SMS approach) or tailoring the SMS content to fit the current needs and preferences of the individuals (eg, allowing participants to opt-in/out for more or less SMS).

Qualitative analyses further demonstrated the importance of adapting and personalization of text messages features currently lacking in many mHealth interventions. ${ }^{42}$ The most consistent view about the text messages was that it should consider participants' preferences regarding message content, frequency, and timing. These themes are consistent with findings from prior studies, which show that implementing personalized text messages can increase the likelihood of behavior change. ${ }^{26,43}$ This finding suggests that the design of text messaging interventions, including the message structure, timing and the frequency of message delivery, and linguistic content, must allow participation and interaction. ${ }^{44}$ A participatory process ensures that the text messaging approach is optimized with a "personal touch" for each individual within a risk group.

Additionally, results revealed that the vast majority of respondents reported preference for two-way text messages. Participants further indicated a willingness to participate in a text messaging-based program that includes multimedia components and reinforcement messages designed to better enhance engagement and to motivate participants to change their behaviors. These findings are in line with evidence from other studies that have stated interactive text messaging not only reminds and motivates 
individuals to take their medications but also allows participants to acknowledge receipt of messages, to respond/ ask questions, and to potentially increase perceived social support. ${ }^{26,45,46}$ The interactive feature of health-related intervention also heightens participants' sense of inherent motivation to not only engage with the technology but also to get more involved in self-care. Interactivity occurs when user is "able to connect and have a reciprocal exchange with other people. ${ }^{, 47}$ Hence, aligning with previous research, this pool of participants demonstrated the need of interactivity of the technology they use. Such findings are promising for future research because the methods that were used help to identify temporal associations and to understand the contextual factors which influence the outcome variables of interest (eg, medication adherence, engagement in drug use- or sex-related behaviors). This will be especially important when replicating this study outside of the MMP setting, where two-way messaging will be more useful in helping to address anticipated challenges with adherence to PrEP. As the field moves closer toward precision medicine, understanding contextual factors can guide the development of just-intime interventions (JITAI) that are tailored to each individual's unique behavioral and contextual needs in real time. $^{48,49}$

\section{Limitations}

Though a number of key findings emerged from this study, several limitations remain. First, a relatively small sample size in the current study somewhat restricted our ability to observe changes in outcomes (eg, PrEP adherence). As a result, the findings presented are more descriptive and we do not have objective outcome data. Second, this study was limited to a single community-based MMP clinic, which limits the generalizability of the findings to active drug users who are not in MMP or receiving opioid treatment in other settings. Therefore, future research could expand to incorporate other study populations (eg, individuals not in treatment and/or not enrolled in MMP) and regions. Third, the use of self-reported data may have generated results that are subject to social desirability bias.

\section{Conclusions}

Notwithstanding these limitations, incorporating text messages in HIV prevention efforts is a promising avenue to reach hard-to-reach, high-risk individuals. Specifically, it has the most appeal as a "reminder" to take PrEP. HIV prevention message may have further benefits if two-way texting was allowed and the content was better tailored to the individual participant. As such, findings from the current study demonstrate that a text message approach is highly feasible, acceptable, and perceived to be helpful among opioid-dependent PWUD at high-risk in a common type of substance use treatment program (ie, MMP). These findings provide us solid foundation for the development of larger randomized controlled trials to evaluate efficacy, sustainability, and cost-effectiveness of text messaging-based HIV prevention interventions.

\section{Ethical Approval}

The study protocol was approved by the Investigational Review Board (IRB) at the University of Connecticut and received board approval from APT Foundation Inc. All procedures performed in studies involving human participants were in accordance with the ethical standards of the institutional and/or national research committee and with the 1964 Helsinki declaration and its later amendments or comparable ethical standards. Informed consent was obtained from all individual participants included in the study.

\section{Acknowledgment}

The abstract of this paper was presented at the 2019 National HIV Prevention Conference as a poster presentation with interim findings. The poster's abstract was published in the "Abstract Book" for the Centers for Disease Control and Prevention. The abstract of this paper was also presented at the Society of Behavioral Medicine 2019 Annual Meeting as a poster presentation with interim findings. The poster's abstract was published in "Poster Abstracts" in Annals of Behavioral Medicine: https://doi. org/10.1093/abm/kaz007.

\section{Funding}

This work was supported by grants from the National Institute on Drug Abuse for research (R01 DA032290 to MMC) and for career development (K24 DA017072 to FLA; K02 DA033139 to MMC).

\section{Disclosure}

The authors have no conflicts of interest to disclose.

\section{References}

1. Peters PJ, Pontones P, Hoover KW, et al. HIV infection linked to injection use of oxymorphone in Indiana, 2014-2015. N Engl J Med. 2016;375(3):229-239. doi:10.1056/NEJMoa1515195 
2. Van Handel MM, Rose CE, Hallisey EJ, et al. County-level vulnerability assessment for rapid dissemination of HIV or HCV infections among persons who inject drugs, United States. J Acquir Immune Defic Syndr. 2016;73(3):323-331. doi:10.1097/QAI.00000000 00001098

3. Substance Abuse and Mental Health Services Administration. Key substance use and mental health indicators in the United States: results from the 2016 national survey on drug use and health. In: Center for Behavioral Health Statistics and Quality, Substance Abuse and Mental Health Services Administration (SAMHSA) NSDUH Data Review. Vol. HHS Publication. No. SMA 17-5044. Rockville, MD: Substance Abuse and Mental Health Services Administration; 2017. Available from: https:/www samhsa gov/data/sites/default/files/ NSDUH-FFR 1-2016/NSDUH-FFR1-2016 htm Published September. Accessed January 8, 2020.

4. Lankenau SE, Teti M, Silva K, Bloom JJ, Harocopos A, Treese M. Patterns of prescription drug misuse among young injection drug users. J Urban Health. 2012;89(6):1004-1016. doi:10.1007/s11524-012-9691-9

5. Jordan AE, Jarlais DD, Hagan H. Prescription opioid misuse and its relation to injection drug use and hepatitis $\mathrm{C}$ virus infection: protocol for a systematic review and meta-analysis. Syst Rev. 2014;3:95. doi:10.1186/2046-4053-3-95

6. Perlman DC, Des Jarlais DC, Feelemyer J. Can HIV and hepatitis C virus infection be eliminated among persons who inject drugs? J Addict Dis. 2015;34(2-3):198-205. doi:10.1080/10550887.2015.1059111

7. Centers for Disease Control and Prevention. Preexposure Prophylaxis for the Prevention of HIV Infection in the United States-2017 Update: A Clinical Practice Guideline. Atlanta, GA: Centers for Disease Control and Prevention; 2017.

8. Grant RM, Lama JR, Anderson PL, et al. Preexposure chemoprophylaxis for HIV prevention in men who have sex with men. $N$ Engl J Med. 2010;363(27):2587-2599. doi:10.1056/NEJMoa1011205

9. Baeten JM, Donnell D, Ndase P, et al. Antiretroviral prophylaxis for HIV prevention in heterosexual men and women. $N$ Engl J Med. 2012;367(5):399-410. doi:10.1056/NEJMoa1108524

10. Thigpen MC, Kebaabetswe PM, Paxton LA, et al. Antiretroviral preexposure prophylaxis for heterosexual HIV transmission in Botswana. $N$ Engl J Med. 2012;367(5):423-434. doi:10.1056/ NEJMoa1110711

11. Van Damme L, Corneli A, Ahmed K, et al. Preexposure prophylaxis for HIV infection among African Women. N Engl J Med. 2012;367 (5):411-422. doi:10.1056/NEJMoa1202614

12. Choopanya K, Martin M, Suntharasamai P, et al. Antiretroviral prophylaxis for HIV infection in injecting drug users in Bangkok, Thailand (the Bangkok Tenofovir Study): a randomised, double-blind, placebo-controlled Phase 3 trial. Lancet. 2013;381 (9883):2083-2090. doi:10.1016/S0140-6736(13)61127-7

13. Dimitrov DT, MÂSse BR, Donnell D. PrEP adherence patterns strongly impact individual HIV risk and observed efficacy in randomized clinical trials. J Acquir Immune Defic Syndr. 2016;72 (4):444-451. doi:10.1097/QAI.0000000000000993

14. Riddell J, Amico K, Mayer KH. Hiv preexposure prophylaxis: a review. JAMA. 2018;319(12):1261-1268. doi:10.1001/jama.2018.1917

15. Ali B, Seitz-Brown CJ, Daughters SB. The interacting effect of depressive symptoms, gender, and distress tolerance on substance use problems among residential treatment-seeking substance users. Drug Alcohol Depend. 2015;148:21-26. doi:10.1016/j.drugalcdep.2014.11.024

16. Shrestha R, Huedo-Medina T, Altice F, Krishnan A, Copenhaver M. Examining the acceptability of mhealth technology in HIV prevention among high-risk drug users in treatment. AIDS Behav. 2016;21 (11):3100-3110

17. Huedo-Medina TB, Shrestha R, Copenhaver M. Modeling a theory-based approach to examine the influence of neurocognitive impairment on HIV risk reduction behaviors among drug users in treatment. AIDS Behav. 2016;20(8):1646-1657. doi:10.1007/s10461016-1394-x
18. Mackesy-Amiti ME, Donenberg GR, Ouellet LJ. Prescription opioid misuse and mental health among young injection drug users. Am J Drug Alcohol Abuse. 2015;41(1):100-106. doi:10.3109/00952 990.2014.940424

19. Sypsa V, Paraskevis D, Malliori M, et al. Homelessness and other risk factors for HIV infection in the current outbreak among injection drug users in Athens, Greece. Am J Public Health. 2015;105 (1):196-204. doi:10.2105/AJPH.2013.301656

20. Free C, Phillips G, Galli L, et al. The effectiveness of mobile-health technology-based health behaviour change or disease management interventions for health care consumers: a systematic review. PLoS Med. 2013;10(1):e1001362. doi:10.1371/journal.pmed.1001362

21. Milward J, Lynskey M, Strang J. Solving the problem of non-attendance in substance abuse services. Drug Alcohol Rev. 2014;33(6):625-636. doi:10.1111/dar.2014.33.issue-6

22. Mbuagbaw L, van der Kop ML, Lester RT, et al. Mobile phone text messages for improving adherence to antiretroviral therapy (ART): an individual patient data meta-analysis of randomised trials. BMJ Open. 2013;3(12):e003950.

23. Shrestha R, Karki P, Copenhaver M. Interest in use of mHealth technology in HIV prevention and associated factors among high-risk drug users enrolled in methadone maintenance program. AIDS Care. 2017;29 (9):1144-1148. doi:10.1080/09540121.2017.1325439

24. Hall AK, Cole-Lewis H, Bernhardt JM. Mobile text messaging for health: a systematic review of reviews. Annu Rev Public Health. 2015;36(1):393-415. doi:10.1146/annurev-publhealth-031914-1228 55

25. Mbuagbaw L, Mursleen S, Lytvyn L, Smieja M, Dolovich L, Thabane L. Mobile phone text messaging interventions for HIV and other chronic diseases: an overview of systematic reviews and framework for evidence transfer. BMC Health Serv Res. 2015;15(1):33. doi:10.1186/s12913-014-0654-6

26. Moore DJ, Jain S, Dubé MP, et al. Randomized controlled trial of daily text messages to support adherence to preexposure prophylaxis in individuals at risk for human immunodeficiency virus: the TAPIR study. Clin Infect Dis. 2018;66(10):1566-1572. doi:10.1093/cid/ cix 1055

27. Montoya JL, Georges S, Poquette A, Depp CA, Atkinson JH, Moore DJ. the translational methamphetamine ARCG: refining a personalized mhealth intervention to promote medication adherence among HIV+ methamphetamine users. AIDS Care. 2014;26 (12):1477-1481. doi:10.1080/09540121.2014.924213

28. Shrestha R, Altice FL, Karki P, Copenhaver MM. Integrated bio-behavioral approach to improve adherence to pre-exposure prophylaxis and reduce HIV risk in people who use drugs: a pilot feasibility study. AIDS Behav. 2018;22:2640-2649. doi:10.1007/ s10461-018-2099-0

29. Shrestha R, Altice F, Karki P, Copenhaver M. Developing an integrated, brief bio-behavioral HIV prevention intervention for high risk drug users in treatment: the process and outcome of formative research. Front Immunol. 2017;8:561. doi:10.3389/fimmu.2017. 00561

30. Dowling-Guyer S, Johnson ME, Fisher DG, et al. Reliability of drug users' self-reported HIV risk behaviors and validity of self-reported recent drug use. Assessment. 1994;1(4):383-392. doi:10.1177/ 107319119400100407

31. Wilson IB, Lee Y, Michaud J, Fowler FJ, Rogers WH. Validation of a new three-item self-report measure for medication adherence. AIDS Behav. 2016;20(11):2700-2708. doi:10.1007/s10461-016-1406-X

32. Tarnowski KJ, Simonian SJ. Assessing treatment acceptance: the abbreviated acceptability rating profile. J Behav Ther Exp Psychiatry. 1992;23(2):101-106. doi:10.1016/0005-7916(92)90007-6

33. Shrestha R, Huedo-Medina TB, Altice FL, Krishnan A, Copenhaver M. Examining the acceptability of mHealth technology in HIV prevention among high-risk drug users in treatment. AIDS Behav. 2017;21(11):3100-3110. doi:10.1007/s10461-016-1637-x 
34. Reback CJ, Ling D, Shoptaw S, Rohde J. Developing a text messaging risk reduction intervention for methamphetamine-using MSM: research note. Open AIDS J. 2010;4:116-122. doi:10.2174/ 1874613601004030116

35. Kim J, Zhang W, Nyonyitono M, et al. Feasibility and acceptability of mobile phone short message service as a support for patients receiving antiretroviral therapy in rural Uganda: a cross-sectional study. J Int AIDS Soc. 2015;18(1):20311. doi:10.7448/IAS.18.1.20311

36. Rana Y, Haberer J, Huang H, et al. Short Message Service (SMS)-based intervention to improve treatment adherence among HIV-positive youth in uganda: focus group findings. PLoS One. 2015;10(4):e0125187. doi:10.1371/journal.pone.0125187

37. Nachega JB, Skinner D, Jennings L, et al. Acceptability and feasibility of mHealth and community-based directly observed antiretroviral therapy to prevent mother-to-child HIV transmission in South African pregnant women under option $\mathrm{B}+$ : an exploratory study. Patient Prefer Adherence. 2016;10:683-690. doi:10.2147/PPA

38. Bonar EE, Cunningham RM, Collins RL, et al. Feasibility and acceptability of text messaging to assess daily substance use and sexual behaviors among urban emerging adults. Addict Res Theory. 2018;26(2):103-113. doi:10.1080/16066359.2017.1310205

39. Dowshen N, Kuhns ML, Johnson A, Holoyda JB, Garofalo R. Improving adherence to antiretroviral therapy for youth living with HIV/AIDS: a pilot study using personalized, interactive, daily text message reminders. J Med Internet Res. 2012;14(2):e51. doi:10.2196/ jmir.2015

40. Patel AR, Kessler J, Braithwaite RS, et al. Economic evaluation of mobile phone text message interventions to improve adherence to HIV therapy in Kenya. Medicine. 2017;96(7):e6078. doi:10.1097/ MD.0000000000006078

41. Siedner MJ, Haberer JE, Bwana MB, Ware NC, Bangsberg DR. High acceptability for cell phone text messages to improve communication of laboratory results with HIV-infected patients in rural Uganda: a cross-sectional survey study. BMC Med Inform Decis Mak. 2012;12:56. doi:10.1186/1472-6947-12-56
42. Head KJ, Noar SM, Iannarino NT, Grant Harrington N. Efficacy of text messaging-based interventions for health promotion: A meta-analysis. Soc Sci Med. 2013;97:41-48. doi:10.1016/j. socscimed.2013.08.003

43. Horvath T, Azman H, Kennedy GE, Rutherford GW. Mobile phone text messaging for promoting adherence to antiretroviral therapy in patients with HIV infection. Cochrane Database Syst Rev. 2012;3: Cd009756.

44. Pérez GM, Hwang B, Bygrave H, Venables E. Designing text-messaging (SMS) in HIV programs: ethics-framed recommendations from the field. Pan Afr Med J. 2015;21:201. doi:10.11604/ pamj.2015.21.201.6844

45. Wald DS, Butt S, Bestwick JP. One-way versus two-way text messaging on improving medication adherence: meta-analysis of randomized trials. Am J Med. 2015;128(10):1139.e1131-1135. doi:10.1016/ j.amjmed.2015.05.035

46. Ware NC, Pisarski EE, Tam M, et al. The meanings in the messages: how SMS reminders and real-time adherence monitoring improve antiretroviral therapy adherence in rural Uganda. Aids. 2016;30 (8):1287-1294. doi:10.1097/QAD.0000000000001035

47. Sundar SS, Bellur S, Jia H. Motivational technologies: a theoretical framework for designing preventive health applications. In: Magnus B, Eva LR, editors Persuasive Technology Design for Health and Safety: 2012//2012. Berlin, Heidelberg: Springer Berlin Heidelberg; 2012:112-122.

48. Nahum-Shani I, Smith SN, Spring BJ, et al. Just-in-Time Adaptive Interventions (JITAIs) in mobile health: key components and design principles for ongoing health behavior support. Ann Behav Med. 2018;52(6):446-462. doi:10.1007/s12160-016-9830-8

49. Spruijt-Metz D, Wen CK, O'Reilly G, et al. Innovations in the use of interactive technology to support weight management. Curr Obes Rep. 2015;4(4):510-519. doi:10.1007/s13679-015-0183-6
Patient Preference and Adherence

\section{Publish your work in this journal}

Patient Preference and Adherence is an international, peer-reviewed, open access journal that focusing on the growing importance of patient preference and adherence throughout the therapeutic continuum. Patient satisfaction, acceptability, quality of life, compliance, persistence and their role in developing new therapeutic modalities and compounds to optimize clinical outcomes for existing disease states are major areas of interest for the journal. This journal has been accepted for indexing on PubMed Central. The manuscript management system is completely online and includes a very quick and fair peer-review system, which is all easy to use. Visit http:// www.dovepress.com/testimonials.php to read real quotes from published authors. 